\title{
Hyperkalemia in neonatal diarrheic calves depends on the degree of dehydration and the cause of the metabolic acidosis but does not require the presence of acidemia
}

\author{
F. M. Trefz, ${ }^{* 1}$ P. D. Constable,† C. Sauter-Louis, ${ }^{*}$ A. Lorch, ${ }^{*}$ G. Knubben-Schweizer, ${ }^{*}$ and I. Lorenzł \\ ${ }^{*}$ Clinic for Ruminants with Ambulatory and Herd Health Services at the Centre for Clinical Veterinary Medicine, LMU Munich, Sonnenstraße 16, \\ 85764 Oberschleißheim, Germany \\ †College of Veterinary Medicine, Purdue University, West Lafayette, IN 47907 \\ fUCD School of Veterinary Medicine, University College Dublin, Belfield, Dublin 4, Ireland
}

\begin{abstract}
Hyperkalemia is a clinically important electrolyte imbalance in neonatal diarrheic calves that has previously been associated with skeletal muscle weakness and life-threatening cardiac arrhythmias. The aim of the present retrospective analysis was to identify risk factors for hyperkalemia in a convenience sample of 832 calves ( $\leq 21 \mathrm{~d}$ of age) with a clinical diagnosis of diarrhea admitted to a veterinary teaching hospital. Plasma potassium concentrations were most closely associated with parameters of dehydration and renal function such as serum creatinine [Spearman correlation $\left(r_{s}\right)=0.61$ ], urea $\left(r_{s}=0.51\right)$, and inorganic phosphorus concentrations $\left(r_{s}=0.64\right)$. Plasma potassium concentrations were weakly associated with venous blood $\mathrm{pH}\left(r_{s}=-0.21\right)$. Although venous blood $\mathrm{pH}$ was not predictive in a multivariate linear regression analysis, the odds of having hyperkalemia $(>5.8 \mathrm{mmol} / \mathrm{L})$ in acidemic calves was found to be 8.6 times as high as in nonacidemic calves [95\% confidence interval (CI): 4.8-15.4]. However, the presence of hyperkalemia depended on the nature of an existing acidosis, and the odds for the presence of hyperkalemia in acidemic calves with hyper-D-lactatemia $(>3.96 \mathrm{mmol} / \mathrm{L})$ were only 0.15 times as high as in acidemic calves with normal D-lactate concentrations (95\% CI, 0.11-0.22). Acidemia in hyperkalemic diarrheic calves was associated with hyponatremia and increased concentrations of inorganic phosphorus, Llactate, and unidentified strong anions that presumably included uremic anions such as sulfate. We conclude that hyper-D-lactatemia in neonatal diarrheic calves is not usually associated with elevated plasma potassium concentrations. Application of the simplified strong ion acid-base model indicated that dehydration is an important contributor to the pathogenesis of hyperkalemia and acidemia in neonatal calves with diarrhea.
\end{abstract}

Received April 20, 2013.

Accepted July 12, 2013.

${ }^{1}$ Corresponding author: Florian.Trefz@campus.lmu.de
Key words: potassium, D-lactate, inorganic phosphorus, strong ion approach

\section{INTRODUCTION}

Dehydration and hyponatremic strong ion (metabolic) acidosis with variable degrees of hyper-D-lactatemia are well-known metabolic and clinicopathologic abnormalities in neonatal calves with diarrhea (Lorenz, 2004; Constable et al., 2005; Lorenz et al., 2005). Hyperkalemia has been described as another clinically important electrolyte disturbance (Fisher and McEwan, 1967) that can result in skeletal muscle weakness and potentially life-threatening cardiac arrhythmias with concomitant progressive atrial standstill and prolonged ventricular depolarization, manifesting as increased QRS duration (Lewis and Phillips, 1973; Weldon et al., 1992; Trefz et al., 2013).

The extracellular potassium concentration represents only $2 \%$ of the total body potassium content (Sterns et al., 1981). Hyperkalemia appears therefore to be a paradoxical finding in neonatal diarrheic calves, because affected animals have a clear negative potassium balance due to intestinal losses and decreased milk intake (Lewis and Phillips, 1972). Hyperkalemia has traditionally been attributed to concomitant acidemia with intracellular buffering of hydrogen ions in exchange for potassium ions and impairment of the $\mathrm{Na}^{+} / \mathrm{K}^{+}$-ATPase (responsible for the distribution of potassium between intracellular and extracellular space) as the main underlying pathophysiological mechanisms (Lewis and Phillips, 1973; Sweeney, 1999; Constable, 2002b). The response of plasma potassium concentration in cases of acute acidemia has been characterized by a linear increase of $0.6 \mathrm{mmol} / \mathrm{L}$ potassium for every 0.1-unit reduction in blood pH (Burnell et al., 1956). However, a systematic review of clinical and experimental studies evaluating the interaction between decreased blood $\mathrm{pH}$ and elevated plasma potassium concentrations revealed a wide variation of the plasma potassium response in acidemic animals (Adrogué and Madias, 1981). A 
noteworthy observation was that acute organic-acid acidosis was not associated with an increase in plasma potassium concentration (Oster et al., 1978; Adrogué et al., 1985). Lactic acidosis, predominantly due to accumulation of D-lactate, is a common finding in neonatal diarrheic calves (Lorenz, 2004), and a recent clinical study reported only a weak correlation between plasma potassium and venous blood $\mathrm{pH}$ in such animals (Trefz et al., 2013). More importantly, dehydration and concomitant impairment of renal function was identified as a key feature of hyperkalemic calves with neonatal diarrhea. However, the role of acid-base abnormalities in the pathogenesis of hyperkalemia in neonatal diarrheic calves is not yet fully understood. The aims of this study were therefore to identify risk factors for hyperkalemia in a large population of neonatal calves with diarrhea and to provide further insights into how acidemia, strong ion (metabolic) acidosis, and dehydration contribute to this clinically important electrolyte imbalance.

\section{MATERIALS AND METHODS}

\section{Calves}

A retrospective study was conducted utilizing the medical records of 832 diarrheic calves up to $21 \mathrm{~d}$ of age admitted to the Clinic for Ruminants, LMU Munich (Oberschleißheim, Germany), between April 2005 and December 2007. The medical records of calves were identified from the electronic database of the clinic and subsequently selected for the study if calves were admitted to the clinic for treatment of diarrhea or had a clinical diagnosis of neonatal diarrhea on initial examination. Venous acid-base status and plasma potassium concentration were determined on arrival. Information retrieved from the medical records included signalment (age, sex, and breed) and the results of venous blood gas analysis, hematologic analysis, and clinical biochemical analysis. Because of regional preferences, most of the calves $(93.0 \%)$ were Simmental, which is the most common dairy breed in Bavaria.

\section{Laboratory Variables}

Laboratory values were determined from blood samples taken from the jugular vein before treatment was administered. Lithium-heparinized blood samples (50 IU of heparin per $\mathrm{mL}$ of blood) were anaerobically collected using a $2-\mathrm{mL}$ polypropylene syringe, and blood $\mathrm{pH}$, partial pressure of carbon dioxide $\left(\mathbf{p C O}_{\mathbf{2}}\right)$, sodium, chloride, potassium, and ionized calcium concentrations were determined using a blood $\mathrm{pH}$, gas, and electrolyte analyzer with ion selective electrodes
(Rapidlab 865 blood gas analyzer, Bayer Vital GmbH, Fernwald, Germany). Blood $\mathrm{pH}$ and $\mathrm{pCO}_{2}$ were corrected for rectal temperature using standard algorithms (Thomas, 1972).

Automatic analyzers were used for hematologic analysis (Sysmex F-820, Sysmex Corp., Kobe, Japan) and serum biochemical analysis (Hitachi 911, Roche Diagnostics, Indianapolis, IN). Blood samples containing lithium heparin (16 IU/mL of blood) and potassium fluoride $(1 \mathrm{~g} / \mathrm{mL}$ of blood) as a glycostatic agent (Major, 1923) were analyzed for concentrations of D-lactate, L-lactate, and glucose. Concentrations of D- and L-lactate were measured by means of enzymatic methods using D- and L-lactate dehydrogenase (Noll, 1966; Lorenz et al., 2003), whereas glucose concentrations were determined by using the hexokinase method (Kunst et al., 1984). Serum samples (plain tubes) were assayed for concentrations of urea (urease method; Talke and Schubert, 1965), creatinine (Jaffé reaction with picric acid; Fabiny and Ertingshausen, 1971), total protein (biuret method; Weichselbaum, 1946), inorganic phosphorus (ammonium molybdate assay; Amador and Urban, 1972), and magnesium (xylidyl blue assay; Mann and Yoe, 1956). Packed cell volume (PCV) was determined using EDTA blood samples. The net charge on magnesium $(\mathrm{mEq} / \mathrm{L})$ was calculated from the total magnesium concentration (mmol/L) assuming $69 \%$ of total magnesium was in the ionized form (Riond et al., 1995). Hyper-D-lactatemia was defined as D-lactate concentration >3.96 mmol/L (Lorenz et al., 2003), plasma potassium concentrations of 3.9 to $5.8 \mathrm{mmol} / \mathrm{L}$ as normokalemia, and acidemia as venous blood $\mathrm{pH}$ $\leq 7.30$ (Kaneko et al., 2008). Information on serum magnesium concentrations was missing in 8 calves; on L-lactate, glucose and phosphorus concentration in 7 calves; on D-lactate concentrations in 6 calves; and on urea, creatinine, and total protein concentrations in 5 calves, respectively. A full data set was available for 821 calves.

\section{Calculations}

Actual bicarbonate concentration $\left(\mathrm{cHCO}_{3}^{-}\right)$was calculated by using the Henderson-Hasselbalch equation with measured blood $\mathrm{pH}$ and $\mathrm{pCO}_{2}$ at $37^{\circ} \mathrm{C}: \mathrm{cHCO}_{3}{ }^{-}$ $=S \times \mathrm{pCO}_{2} \times 10^{\left(\mathrm{pH}-\mathrm{p} K 1^{\prime}\right)}$. Values for the negative logarithm of the dissociation constant of carbonic acid $\left(\mathrm{p} K_{1}{ }^{\prime}\right)$ and solubility of carbon dioxide $(S)$ for plasma were 6.105 and $0.0307 \mathrm{mmol} / \mathrm{L}$ per $\mathrm{mm} \mathrm{Hg}$, respectively. After measuring the hemoglobin concentration $(\mathbf{H b} ; \mathrm{mg} / \mathrm{dL})$ photometrically, blood base excess (in vitro base excess) was calculated $(\mathrm{mmol} / \mathrm{L})$ using the van Slyke equation (Siggaard-Andersen, 1977) with measured blood $\mathrm{pH}$ at $37^{\circ} \mathrm{C}$ and the calculated actual 
bicarbonate concentration: Base excess $=(1-0.014$ $\times \mathrm{Hb}) \times\left[\left(\mathrm{HCO}_{3}^{-}-24.8\right)+(1.43 \times \mathrm{Hb}+7.7) \times\right.$ $(\mathrm{pH}-7.4)]$. An estimate of the unmeasured anion concentration was obtained by calculating the anion gap $(\mathbf{A G} ; \mathrm{mEq} / \mathrm{L}): \mathrm{AG}=\left[\mathrm{Na}^{+}\right]+\left[\mathrm{K}^{+}\right]-\left[\mathrm{Cl}^{-}\right]-\left[\mathrm{HCO}_{3}{ }^{-}\right]$.

In addition to the traditional Henderson-Hasselbalch model, the simplified quantitative physicochemical strong ion approach (Constable, 1997) was used to identify likely mechanisms for acid-base abnormalities in this study population. Measured strong ion difference was calculated from the measured values for 7 strong ions $\left(\mathbf{S I D}_{7}, \mathrm{mEq} / \mathrm{L}\right.$; Müller et al., 2012) and using the measured value for $\left[\mathrm{Ca}^{2+}\right]$ determined by ion selective potentiometry and assigning a charge of +1.38 to magnesium assuming 69\% dissociation (Riond et al., 1995) and -1 to D-lactate and L-lactate, such that $\mathrm{SID}_{7}=$ $\left[\mathrm{Na}^{+}\right]+\left[\mathrm{K}^{+}\right]+\left[\mathrm{Mg}^{2+}\right]+\left[\mathrm{Ca}^{2+}\right]-\left[\mathrm{Cl}^{-}\right]-[$L-lactate $]-$ [D-lactate]. The concentration of nonvolatile weak acids $\left(\mathbf{A}_{\text {tot }} ; \mathrm{mmol} / \mathrm{L}\right)$ was calculated from the serum concentrations of total protein $(\mathrm{g} / \mathrm{L})$ according to experimentally determined values for calf plasma (Constable et al., 2005): $\mathrm{A}_{\text {tot }}=0.343 \times$ [total protein]. An estimate of the unmeasured strong ion concentration was obtained by calculating the strong ion gap $(\mathbf{S I G} ; \mathrm{mEq} / \mathrm{L})$, which is defined as the difference between the plasma concentration of unmeasured strong cations and unmeasured strong anions (Constable, 2000). This was performed using the calculated value for $A_{\text {tot }}$, the experimentally determined value for the negative logarithm of dissociation constant of plasma nonvolatile weak acids $\left(\mathbf{p} \boldsymbol{K}_{\mathrm{a}}\right)$ in calf plasma ( $\left.\mathrm{p} K_{\mathrm{a}}=7.08\right)$, and the following equation (Constable et al., 2005): SIG $=\left[\mathrm{A}_{\text {tot }} /\left(1+10^{(7.08-\mathrm{pH})}\right)\right]$ - AG. The first expression on the right-hand-side of the SIG equation represents the net negative charge $(\mathrm{mEq} / \mathrm{L})$ of nonvolatile weak acids in plasma. Strong ion gap was corrected for the measured concentrations of D- and L-lactate and $\left[\mathrm{Mg}^{2+}\right]$ and $\left[\mathrm{Ca}^{2+}\right]$ (expressed in $\mathrm{mEq} / \mathrm{L}$ ) to obtain the concentration of unidentified strong ions (USI, $\mathrm{mEq} / \mathrm{L}$; Müller et al., 2012): USI = SIG $+[$ D-lactate $]+[$ L-lactate $]-\left[\mathrm{Mg}^{2+}\right]-\left[\mathrm{Ca}^{2+}\right]$. The effective strong ion difference $\left(\mathbf{S I D}_{\text {eff }} ; \mathrm{mEq} / \mathrm{L}\right)$, which provides an estimate of the true SID, was calculated as $\mathrm{SID}_{\text {eff }}=\mathrm{SID}_{7}+$ USI (Müller et al., 2012).

\section{Statistical Analysis}

The software package PASW Statistics 18.0 (IBM, New York, NY) was used for statistical analysis. Values of $P<0.05$ were considered to be statistically significant. Because most of the data were not normally distributed, nonparametric tests were used and data are presented as medians and interquartile ranges. Mann-Whitney U-tests were used for comparisons between groups. Spearman correlation coefficients $\left(\boldsymbol{r}_{s}\right)$ were calculated to determine associations between parameters. Weak, moderate, and strong correlations were defined as correlation coefficients of 0 to 0.39 , 0.40 to 0.59 , and 0.6 to 1.0 , respectively. The results of a simple linear regression analysis were displayed. Differences between 2 correlation coefficients were assessed by using Fisher $z$-transformation (http://www. vassarstats.net/rdiff.html). Stepwise forward multiple linear regression models were constructed, including measured variables of clinical pathology significantly correlated with the dependent variables. If the calculated Spearman rho coefficient between 2 variables was greater than 0.75 , the variable that had the highest coefficient of correlation in the univariable analysis was the only one entered into the model to minimize the effects of collinearity. The relative importance of the included variables was assessed by the order of entry as well as by the change of the model $R^{2}$ value $(\Delta$ $\mathrm{R}^{2}$ ). The residuals of the linear regression models were tested for normal distribution. The models were calculated with raw and log-transformed data; the analysis on raw data is presented because the log-transformed data did not yield a better model fit. A receiver operating characteristics analysis was performed to identify optimal cut-off values of potentially useful predictors of a hypo- $(<3.9 \mathrm{mmol} / \mathrm{L})$ or hyperkalemic state $(>5.8$ $\mathrm{mmol} / \mathrm{L})$. Those cut-off values and the given reference ranges for D-lactate and venous $\mathrm{pH}$ were used to recode the laboratory parameters into categorical variables to calculate odds ratios with associated $95 \%$ confidence intervals $(95 \% \mathrm{CI})$.

\section{RESULTS}

The median value and interquartile range for age were $9.4(7.0-12.2)$ d. Hyperkalemia was present in 234 calves $(28.1 \%)$, normokalemia in 504 calves $(60.6 \%)$, and hypokalemia in 94 calves (11.3\%). No sex-specific differences were found for plasma $\mathrm{K}^{+}$concentration.

The highest coefficients of correlation were between plasma $\mathrm{K}^{+}$concentration and serum inorganic phosphorus concentration (Figure 1), as well as serum creatinine, magnesium, urea, and plasma L-lactate concentration (Table 1). Only weak correlations existed between plasma $\mathrm{K}^{+}$concentration and venous blood $\mathrm{pH}$, base excess, and plasma bicarbonate concentration. However, in calves with normal D-lactate concentrations, plasma $\mathrm{K}^{+}$concentration and venous blood $\mathrm{pH}$ were strongly correlated $\left(r_{s}=-0.62, P<0.001\right)$ with a mean increase of $0.65 \mathrm{mmol} / \mathrm{L} \mathrm{K}^{+}$(95\% CI: $\left.0.57-0.73\right)$ for every 0.1-unit reduction in venous blood $\mathrm{pH}$ (Figure 2). In contrast, in calves with hyper-D-lactatemia, plasma $\mathrm{K}^{+}$concentration and venous blood $\mathrm{pH}$ were only weakly associated $\left(r_{s}=-0.17, P<0.001\right)$ with a 
Table 1. Median and interquartile range $\left(\mathrm{Q}_{25} / \mathrm{Q}_{75}\right)$ for selected serum or plasma concentrations of laboratory variables, and Spearman's correlation coefficient $\left(r_{s}\right)$ with plasma potassium concentration in calves of the study population

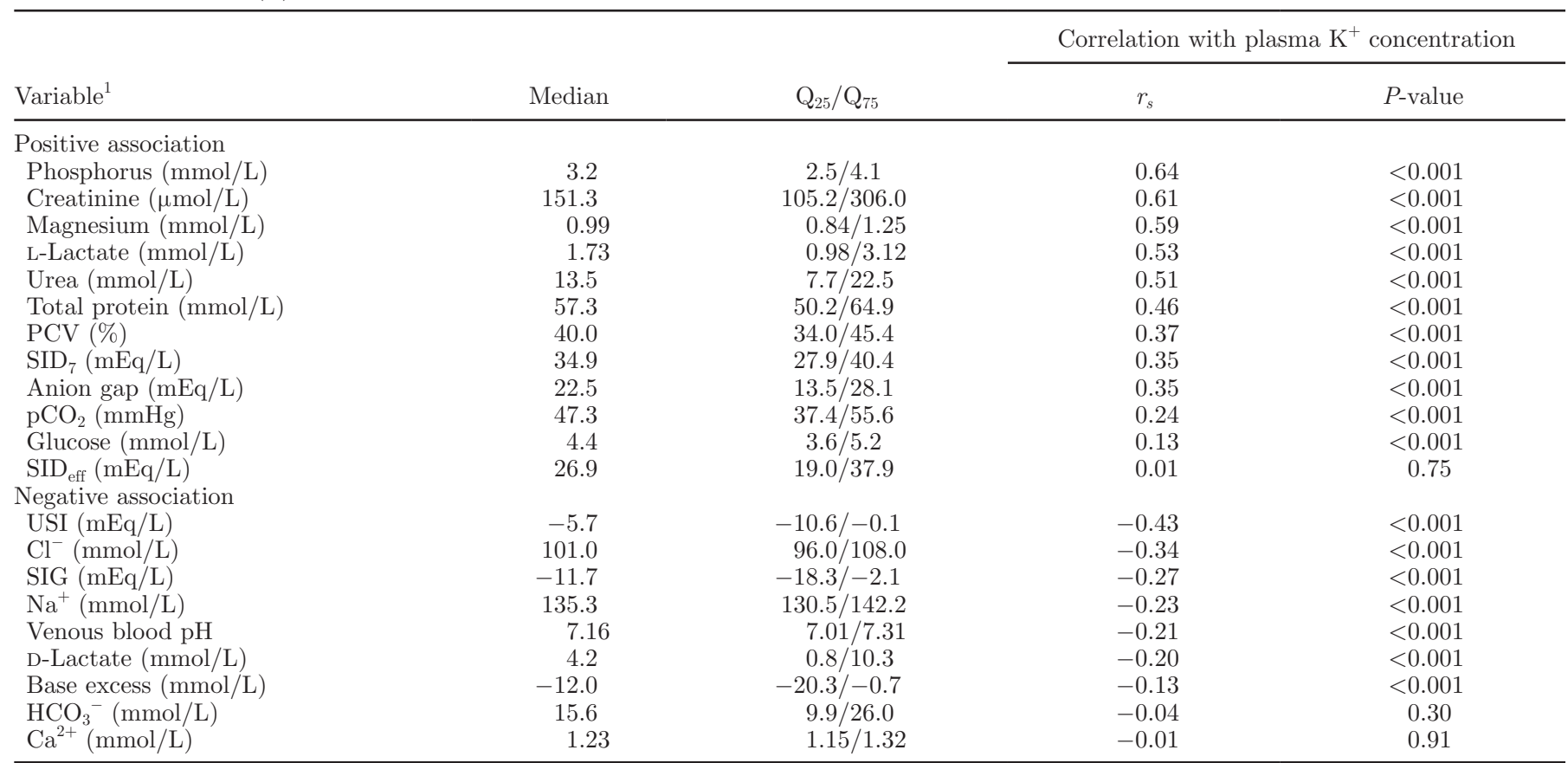

${ }^{1} \mathrm{PCV}=$ packed cell volume; $\mathrm{SID}_{7}=$ strong ion difference calculated from 7 strong cations and anions; $\mathrm{pCO}_{2}=$ partial pressure of $\mathrm{CO}_{2} ; \mathrm{SID}_{\text {eff }}=$ effective strong ion difference; USI = unmeasured strong ions; SIG $=$ strong ion gap.

mean increase of $0.18 \mathrm{mmol} / \mathrm{L} \mathrm{K}^{+}(95 \% \mathrm{CI}, 0.09-0.26)$ for every 0.1-unit reduction in venous blood $\mathrm{pH}$ (Figure 3). Additionally, the coefficients of correlation between plasma $\mathrm{K}^{+}$concentration and serum concentrations of creatinine, urea, and phosphorus differed $(P<0.001)$

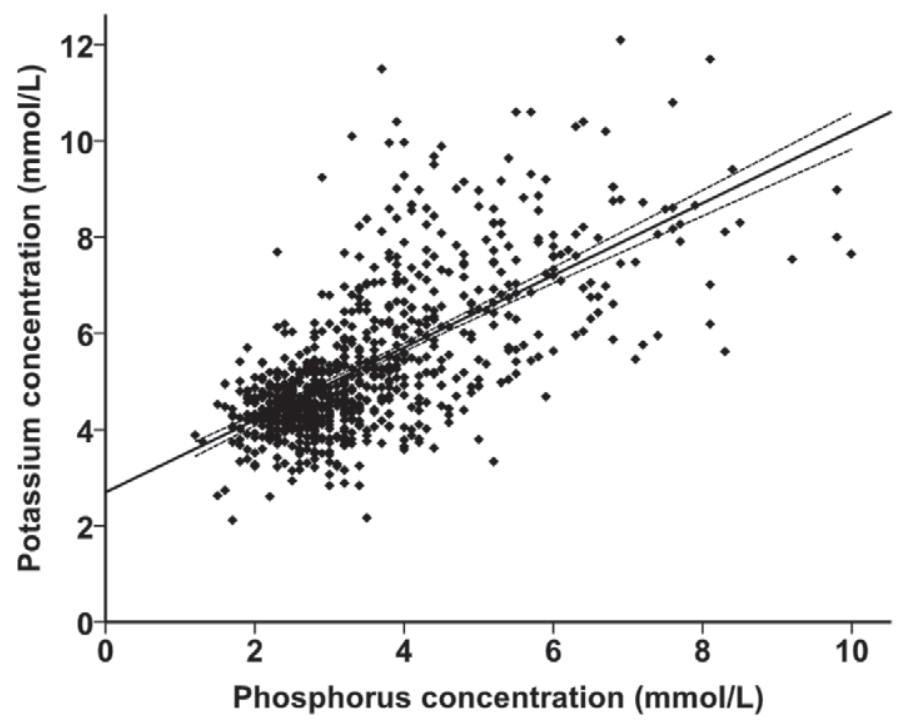

Figure 1. Scatterplot of plasma potassium and serum phosphorus concentrations in 825 neonatal calves with diarrhea. The solid line represents the results of a linear regression analysis and the dashed lines indicate the $95 \%$ CI of the slope estimate. between calves with normal D-lactate concentrations $\left(r_{s}\right.$ $=0.73,0.64,0.74)$ and calves with elevated D-lactate concentrations $\left(r_{s}=0.51,0.43,0.60\right)$, respectively.

To predict plasma $\mathrm{K}^{+}$concentration, venous $\mathrm{pH}$ (as a global index of acid-base status), $\mathrm{pCO}_{2}$ (an index of respiratory status), inorganic phosphorus, creatinine, and total protein concentrations, PCV (as proxies for hydration status and renal function), and concentrations of D-lactate, L-lactate, glucose, sodium, and chloride were entered into a multiple stepwise linear regression model. Urea and magnesium were not included into the model because they were strongly correlated $\left(r_{s}>0.75\right)$ with creatinine and inorganic phosphorus, respectively. The results of this analysis are presented in Table 2 . Venous $\mathrm{pH}$ and $\mathrm{PCV}$ were nonsignificant as predictors, and the final model explained $62 \%$ of the variation of plasma $\mathrm{K}^{+}$concentration, with serum inorganic phosphorus concentration having the highest explanatory power.

According to this analysis, azotemia and hyperphosphatemia were identified as risk factors for hyperkalemia. The odds for having hyperkalemia in calves with an inorganic phosphorus concentration $>3.4 \mathrm{mmol} / \mathrm{L}$ were 21.5 times as high as for calves with an inorganic phosphorus concentration $\leq 3.4 \mathrm{mmol} / \mathrm{L} \quad(95 \%$ CI: 14.2-32.6; $P<0.001)$. Additionally, the odds ratios of hyperkalemia for azotemic calves (serum creatinine concentration $>200 \mu \mathrm{mol} / \mathrm{L}$ and serum urea concentra- 


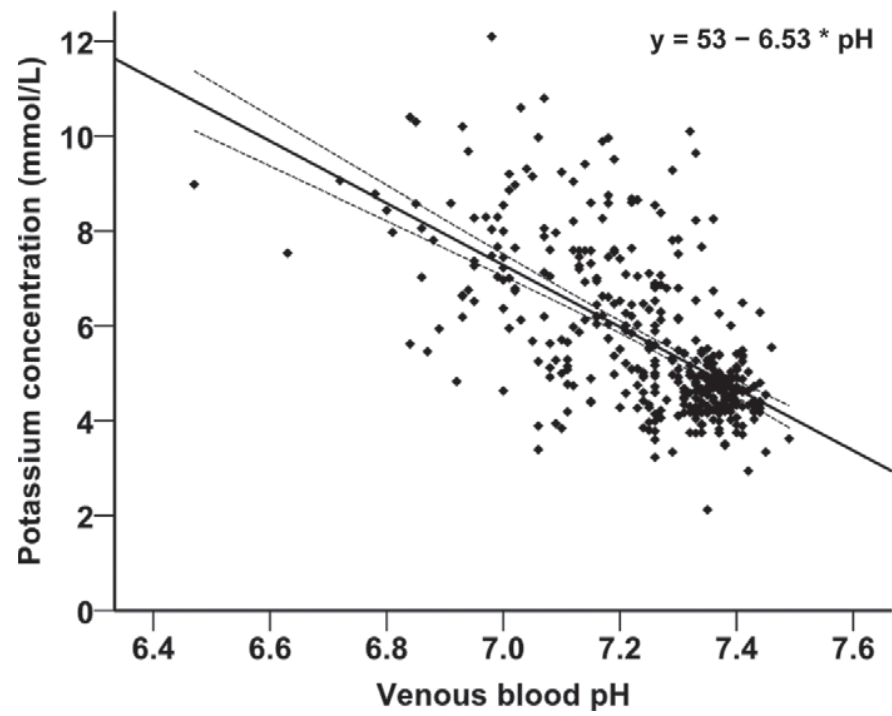

Figure 2. Scatterplot of venous blood $\mathrm{pH}$ and plasma potassium concentrations in 402 neonatal calves with diarrhea and normal plasma concentrations of D-lactate $(\leq 3.96 \mathrm{mmol} / \mathrm{L})$. The line represents the results of a linear regression analysis (dashed lines indicate the 95\% CI of the slope). This analysis revealed a coefficient of correlation of $-0.63(P<0.001)$, which is numerically similar to the calculated Spearman rho coefficient of $-0.62(P<0.001)$.

tion $>17 \mathrm{mmol} / \mathrm{L}$ ) were 26.9 (95\% CI: 17.4-41.4; $P<$ $0.001)$ and 13.4 (95\% CI, 9.2-19.4; $P<0.001)$, respectively, compared with calves with serum creatinine and urea concentrations below those cut-off values.

Acidemia was found in $94.4 \%$ of calves with hyperkalemia $(221 / 234)$. Therefore, the odds for the presence of hyperkalemia in calves with acidemia were 8.6 times as high as in calves without acidemia (95\% CI: 4.8-15.4; $P<0.001)$. However, the presence of hyperkalemia depended on the nature of an existing strong ion acidosis as only $35.8 \%$ of calves with acidemia (221/618) suffered from hyperkalemia. The odds for elevated $\mathrm{K}^{+}$ in acidemic calves with L-lactate concentrations $>1.9$

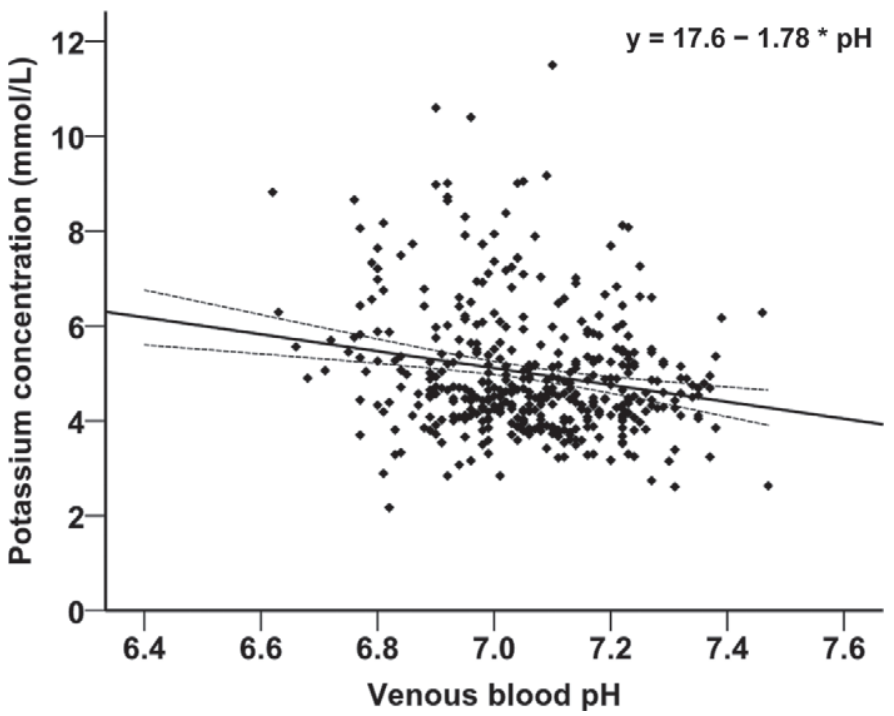

Figure 3. Scatterplot of venous blood $\mathrm{pH}$ and plasma potassium concentrations in 424 neonatal calves with diarrhea and an elevated plasma D-lactate concentration. The lines represent the results of a linear regression analysis (dashed lines indicate the $95 \%$ CI of the slope). This analysis revealed a coefficient of correlation of $-0.20(P<0.001)$, which is numerically similar to the calculated Spearman rho coefficient of $-0.17(P<0.001)$.

$\mathrm{mmol} / \mathrm{L}$ were 11.3 times as high as in acidemic calves with L-lactate concentrations $\leq 1.9 \mathrm{mmol} / \mathrm{L}(95 \% \mathrm{CI}$ : 7.6-16.7; $P<0.001)$. A nonvolatile weak acid acidosis was also associated with the presence of hyperkalemia because the odds in acidemic calves with a calculated $\mathrm{A}_{\text {tot }}>19.7 \mathrm{mmol} / \mathrm{L}$ were 8.4 times as high as in acidemic calves with $\mathrm{A}_{\text {tot }} \leq 19.7 \mathrm{mmol} / \mathrm{L}$ (95\% CI: 5.5-12.8; $P<0.001)$. Acidemic calves with hyper-D-lactatemia $(>3.96 \mathrm{mmol} / \mathrm{L}$ ) had lower odds for hyperkalemia (only 0.15 times as high as in acidemic calves with normal Dlactate concentrations; 95\% CI: $0.11-0.22 ; P<0.001)$ but higher odds for hypokalemia (odds ratio $=4.5,95 \%$ CI: $2.2-9.2 ; P<0.001)$.

Table 2. Multiple linear regression model for predicting plasma potassium concentration in 821 neonatal calves with diarrhea ${ }^{1}$

\begin{tabular}{|c|c|c|c|c|c|c|}
\hline $\begin{array}{l}\text { Order of } \\
\text { entry }\end{array}$ & Variable $^{2}$ & Coefficient & $\pm \mathrm{SE}$ & $P$-value & $\Delta \mathrm{R}^{2}$ & Model $\mathrm{R}^{2}$ \\
\hline & Constant & 5.081 & 0.509 & $<0.001$ & - & - \\
\hline 1 & Phosphorus & 0.413 & 0.038 & $<0.001$ & 0.448 & 0.448 \\
\hline 3 & D-Lactate & -0.020 & 0.008 & 0.018 & 0.042 & 0.566 \\
\hline 4 & Sodium & -0.050 & 0.007 & $<0.001$ & 0.020 & 0.586 \\
\hline 5 & L-lactate & 0.100 & 0.017 & $<0.001$ & 0.012 & 0.599 \\
\hline 8 & Glucose & -0.041 & 0.015 & 0.006 & 0.003 & 0.621 \\
\hline 9 & $\mathrm{pCO}_{2}$ & 0.009 & 0.004 & 0.027 & 0.002 & 0.623 \\
\hline
\end{tabular}

${ }^{1}$ Only calves with a full data set were included in the analysis. $\Delta \mathrm{R}^{2}=$ increase in $\mathrm{R}^{2}$ caused by the addition of the variable to the multiple linear regression model.

${ }^{2}$ Venous $\mathrm{pH}$ and packed cell volume were eliminated at the $\alpha=5 \%$ level. $\mathrm{pCO}_{2}=$ partial pressure of $\mathrm{CO}_{2}$. 
To characterize the nature of an existing strong ion acidosis in hyperkalemic and nonhyperkalemic calves, selected clinicopathological variables of acidemic calves were compared between those groups (Table 3). Acidemic calves with hyperkalemia had lower D-lactate concentrations than nonhyperkalemic calves, and a clear negative correlation between plasma $\mathrm{K}^{+}$concentration and D-lactate $\left(r_{s}=-0.45 ; P<0.001\right)$ was seen in acidemic calves. In contrast, compared with those acidemic calves with normo- or hypokalemia, hyperkalemic calves had significantly higher plasma or serum concentrations of L-lactate, inorganic phosphorus, and total protein and higher values of $\mathrm{pCO}_{2}, \mathrm{SID}_{7}, \mathrm{SID}_{\text {eff }}$, $\mathrm{A}_{\text {tot }}$, and $\mathrm{AG}$, and more negative values of SIG.

The values of $\mathrm{pCO}_{2}$, D-lactate, L-lactate, total protein, sodium, chloride, and inorganic phosphorus were entered in a second stepwise multiple linear regression model that aimed to predict venous blood $\mathrm{pH}$ in either hyperkalemic calves or nonhyperkalemic calves (Table 4). In nonhyperkalemic calves, the acidemia could be mainly explained by elevated D-lactate concentration, but hyperphosphatemia had a major effect on venous blood $\mathrm{pH}$ in hyperkalemic calves. The models explained 72 and $77 \%$ of the variation of venous blood $\mathrm{pH}$ in hyperkalemic and nonhyperkalemic calves, respectively. Inclusion of $\mathrm{A}_{\text {tot }}$ instead of total protein and inorganic phosphorus would have resulted in a lower fit of the models $\left(\mathrm{R}^{2}=0.53\right.$ for hyperkalemic calves and $\mathrm{R}^{2}=$ 0.67 for nonhyperkalemic calves).

\section{DISCUSSION}

This retrospective analysis demonstrates that many factors other than an increase in plasma hydrogen ion activity are associated with hyperkalemia in neonatal diarrheic calves. According to our previous analysis (Trefz et al., 2013), azotemia and hyperphosphatemia were identified as the main risk factors for hyperkalemia; these findings strongly indicated that hypovolemia and a concomitant decrease of glomerular filtration rate play a key role in the pathogenesis of hyperkalemia in such animals. Potassium filtered at the glomeruli is almost entirely reabsorbed by the proximal tubule cells, such that potassium excretion strictly depends on secretion by the distal tubules in exchange for sodium and chloride ions (Brobst, 1986; Sweeney, 1999). Experimental studies in rats have shown that this process is strongly influenced by urine flow and distal tubular delivery of sodium (Good and Wright, 1979; Good et al., 1984). Therefore, an increased proximal tubular reabsorption of sodium and water in response to hypovolemia and a decrease in glomerular filtration rate due to hypovolemia result in reduced distal tubular potassium secretion and thereby an increased risk for

Table 3. Median and interquartile range $\left(\mathrm{Q}_{25} / \mathrm{Q}_{75}\right)$ for acid-base variables of 618 neonatal calves with diarrhea and acidemia (venous blood $\mathrm{pH}$ $\leq 7.30)$ in relation to plasma potassium concentration

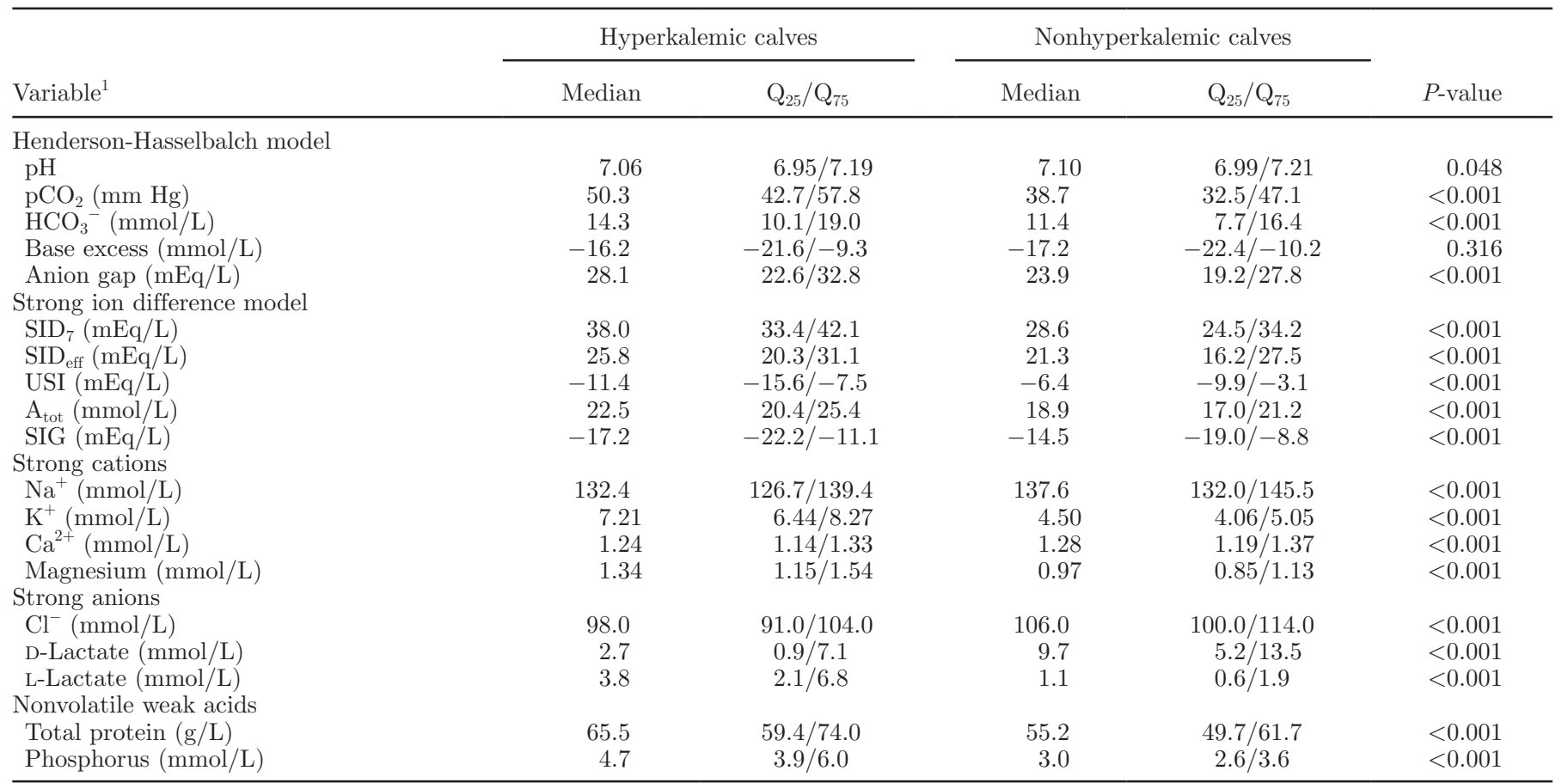

${ }^{1} \mathrm{pCO}_{2}=$ partial pressure of $\mathrm{CO}_{2} ; \mathrm{SID}_{7}=$ strong ion difference calculated from 7 strong cations and anions; SID eff $=$ effective strong ion difference; USI = unmeasured strong ions; $\mathrm{A}_{\text {tot }}=$ concentration of nonvolatile weak acids; SIG = strong ion gap. 


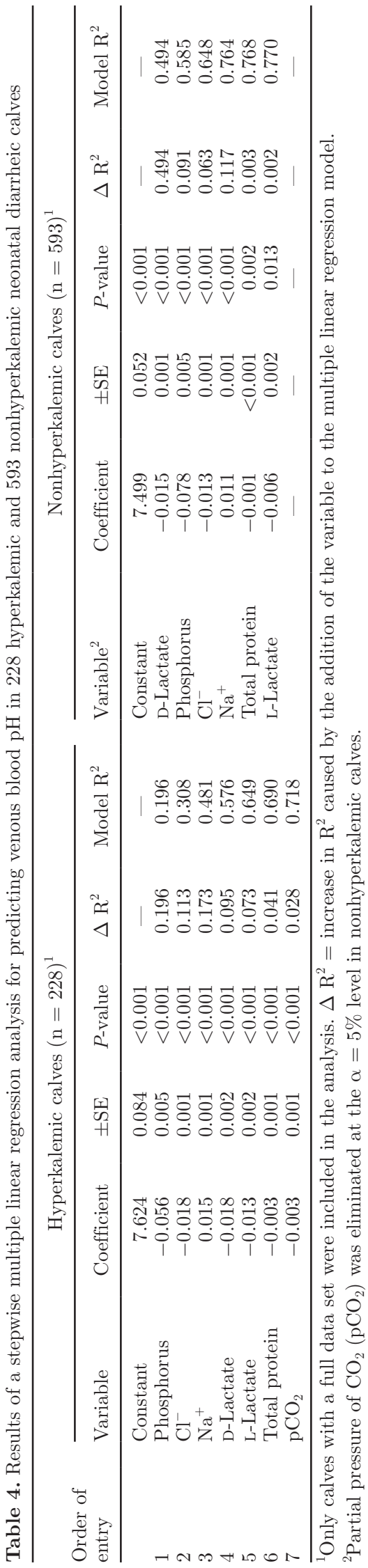

hyperkalemia in calves with prerenal azotemia. This effect is further enhanced by systemic acidemia causing an efflux of potassium ions out of renal tubular cells, which decreases the potassium concentration gradient toward the tubular lumen and therefore potassium secretion (Cemerikić et al., 1982; Aronson and Giebisch, 2011).

Although venous blood $\mathrm{pH}$ had no predictive value for plasma $\mathrm{K}^{+}$in the multivariate regression analysis, the odds for the presence of hyperkalemia in acidemic calves were found to be 8.6 times as high as in nonacidemic calves. However, substantial differences existed between the various types of metabolic acidosis with regard to a potential increase in plasma potassium concentration. In particular, the fact that venous blood $\mathrm{pH}$ and plasma $\mathrm{K}^{+}$concentration were negligibly correlated in calves with elevated plasma D-lactate concentrations may indicate that D-lactatemia is a protective factor for hyperkalemia in diarrheic calves. To explain this phenomenon, several aspects have to be taken into account. First, D-lactic acidosis in calves is not necessarily associated with clinical dehydration. The clinical picture of this condition has long been known as "acidosis without dehydration syndrome" (Kasari and Naylor, 1984, 1986) and was clearly attributed to D-lactic acidosis in 1998 (Schelcher et al., 1998). Therefore, renal elimination of potassium ions in calves with no or only slight dehydration might play a substantial role in limiting the acidosis-induced increase of the extracellular potassium concentration and may explain normokalemia despite a marked D-lactic acidosis (Figure 3). Unfortunately, the plasma potassium concentration does not always accurately reflect the whole-body potassium content in cases of an acid-base disturbance (Brobst, 1986). Further studies appear to be required to determine whether normo- or hypokalemia in spite of a marked D-lactic acidosis is associated with a depletion of the body potassium content, as would occur by renal $\mathrm{K}^{+}$ wasting during ongoing acidosis.

Second, in the present study, the coefficients of correlation between plasma $\mathrm{K}^{+}$and parameters of renal function (serum urea, creatinine, and inorganic phosphorus concentration) were lower in calves with hyperD-lactatemia than in calves with normal D-lactate concentrations. In vitro studies in rats reported an increased potassium secretion when impermeant anions such as sulfate, acetate, and bicarbonate were present in the lumen of the distal tubular system (Velázquez et al., 1982; Amorim et al., 2003). These anions are proposed to increase the electronegativity of the tubular fluid when sodium is reabsorbed at this site, which subsequently results in increased potassium secretion (Clark and Brown, 1995). Because there is a high renal elimination of D-lactate in diarrheic calves (Grude, 
2003; Ewaschuk et al., 2004; Lorenz et al., 2005), it is conceivable that this process may favor kaliuresis. Therefore, calves with a D-lactic acidosis may still be able to eliminate potassium ions sufficiently despite an existing impairment of glomerular filtration rate.

Third, experimental studies in dogs have demonstrated that the presence of hyperkalemia depends on the type of metabolic acidosis. Infusions with mineral acids (such as $\mathrm{HCl}$ or $\mathrm{NH}_{4} \mathrm{Cl}$ ) produced hyperkalemia, whereas infusions with organic acids [ketoacid or lactic acid (not specified but probably a racemic mixture of $\mathrm{L}$ - and D-lactate)] resulted in normo- or hypokalemia (Oster et al., 1978, 1980; Adrogué et al., 1985). Although a shortterm induced severe hyperchloremic acidosis failed to induce hyperkalemia in calves (Gentile et al., 2008), a meta-analysis of the plasma potassium response in acidemic humans and animals revealed that only acute mineral acid acidosis was associated with a mean increase of $0.66 \mathrm{mmol} / \mathrm{L} \mathrm{K}^{+}$(range: 0.2 to $1.7 \mathrm{mmol} / \mathrm{L}$ ) per every 0.1-unit reduction in blood $\mathrm{pH}$ (Adrogué and Madias, 1981). Because acute organic acid acidosis was also not associated with a change in $\mathrm{K}^{+}$in their review, those results are almost identical to our findings (Figures 2 and 3). The reasons why experimentally induced organic acid acidosis resulted in normo- or hypokalemia have not been completely clarified. Adrogué et al. (1985) suggested hormonal mechanisms and proposed that cellular uptake of potassium was enhanced by hyperinsulinemia during ketoacid infusion, whereas release of potassium was assumed to result from increased glucagon concentrations during $\mathrm{HCl}$ acidosis. However, the disparate effect of hydrochloric versus organic acid on the extracellular $\mathrm{K}^{+}$concentration was also observed under in vitro conditions (Rogers and Wachenfeld, 1958; Graber, 1993), indicating that it can also occur in the absence of endocrinological influences. Rogers and Wachenfeld (1958) suggested that organic acids are able to enter the intracellular space, especially as intact undissociated acids. Under this condition, intracellular electroneutrality is maintained and potassium ions do not need to leave the cells. Newer explanations state that lactic acidosis causes a strong intracellular flux of lactate and $\mathrm{H}^{+}$ions through the monocarboxylate transporter, which results in a decrease of intracellular $\mathrm{pH}$. This effect is counterbalanced by an $\mathrm{Na}^{+} /$ $\mathrm{H}^{+}$exchange, making extra sodium available for the $\mathrm{Na}^{+} / \mathrm{K}^{+}$-ATPase, which causes a net cellular uptake of $\mathrm{K}^{+}$(Aronson and Giebisch, 2011). In addition to the discussed mechanisms, this phenomenon appears to explain the negative correlation between plasma potassium and D-lactate concentrations in calves with acidemia, as well as hypokalemia in some calves with marked D-lactic acidosis. The latter may reflect intestinal losses of potassium or lack of intake of milk and potassium containing oral rehydration solutions.

Acidemia in calves with diarrhea has recently been attributed to strong ion acidosis due to hyponatremia accompanied with normo- or hyperchloremia and an increase of unmeasured strong anions such as D-lactate (Constable et al., 2005). A nonvolatile weak acid acidosis due to increases in serum protein concentrations was reported to contribute to the acidemia when calves become dehydrated. To fully characterize the mechanism for acidemia in hyperkalemic and nonhyperkalemic calves, we compared laboratory values between the 2 groups. Significantly higher calculated values for $\mathrm{A}_{\text {tot }}$ in hyperkalemic calves indicated the presence of a nonvolatile weak acid acidosis in hyperkalemic calves (Table 3). An interesting finding was that hyperkalemic calves had higher values of SIG and AG despite significantly lower plasma D-lactate concentrations than nonhyperkalemic calves. This could be only partly explained by elevated plasma L-lactate concentrations in hyperkalemic calves. Correcting the SIG with the measured concentrations for the strong anions D- and L-lactate revealed a median concentration of unidentified anions of $-11.4 \mathrm{mEq} / \mathrm{L}$ that exacerbated the acidemia by decreasing the SID $_{\text {eff }}$ in those calves. The nature of these anions remains unclear but it is likely that their accumulation resulted from severe dehydration and concomitant prerenal azotemia. Elevated plasma concentrations of sulfate, urate, oxalate, hippurate, and other strong anions have been associated with azotemia (Niwa, 1996). Elevated phosphorus concentration likely further contributed to this finding because the anion charge of phosphate ions was not considered in the calculation of the SIG, which uses the experimentally determined species-specific value of $\mathrm{A}_{\text {tot }}$, which is derived from the total protein concentration (Constable et al., 2005). However, this method is only valid if the change in the 3 constituents of $A_{\text {tot }}$ (i.e., globulin, albumin, and phosphate) is similar in magnitude and direction (Constable, 2002a). Because total protein and inorganic phosphorus were only moderately correlated in this study population $\left(r_{s}=0.55, P<0.001\right)$, it was of interest to know how serum proteins and phosphate concentration themselves contributed to the acidemia found in hyperkalemic calves. For that purpose, we performed a stepwise multiple linear regression analysis that aimed to predict venous blood $\mathrm{pH}$ in hyperkalemic and nonhyperkalemic calves. This analysis identified inorganic phosphorus as the most important predictor of blood $\mathrm{pH}$ in dehydrated diarrheic calves.

A likely cause for the increased serum inorganic phosphorus concentration in diarrheic calves was dehydration and prerenal azotemia. Hyperphosphatemia in 
adult cattle with abomasal volvulus or right displaced abomasum appears to result from dehydration and decreased renal blood flow and glomerular filtration rate (Grünberg et al., 2005). It has been recommended that hyperphosphatemia in adult cattle is best corrected by rehydrating the animal and normalizing renal blood flow (Grünberg et al., 2005), and this treatment recommendation appears appropriate for dehydrated diarrheic calves with hyperphosphatemia. Acute acidemia may also have been responsible for part of the increased serum phosphorus concentration because tissue hypoxia can lead to anaerobic glycolysis, intracellular acidosis, and intracellular breakdown of high energy organic phosphate compounds (Opie et al., 1972; O'Connor et al., 1977). Chronic acidemia was considered an unlikely cause for hyperphosphatemia in the calves of the present study population because chronic acidemia and metabolic acidosis in humans resulted in a negative phosphorus balance and a small decrease in serum phosphorus concentration due to increased urinary phosphorus loss (Lemann et al., 1966). Studies investigating the effect of mild metabolic acidosis in cows during late gestation suggest that mild to moderate acidemia and metabolic acidosis may cause a slight increase in plasma phosphorus concentration (Grünberg et al., 2011) but this has not been consistently observed (Joyce et al., 1997; Gasperlin et al., 2002).

Application of SID theory to healthy and diarrheic calves calculated that at normal venous blood $\mathrm{pH}$ (7.38), a decrease of $1 \mathrm{mEq} / \mathrm{L}$ in SID would decrease $\mathrm{pH}$ by 0.013 units, a decrease of $1 \mathrm{mmHg}$ in $\mathrm{pCO}_{2}$ would increase $\mathrm{pH}$ by 0.007 units, and a decrease of $1 \mathrm{~g} / \mathrm{L}$ in total protein would increase $\mathrm{pH}$ by 0.001 units (Constable et al., 2005). These estimated coefficient values were remarkably similar to the adjusted coefficient estimates for strong cations (sodium, +0.015, +0.011), strong anions (chloride, $-0.018,-0.013$; D-lactate, -0.018 , -0.015 ; L-lactate, $-0.013,-0.006)$, and nonvolatile buffer ions (total protein, $-0.003,-0.001$ ) obtained for hyperkalemic and nonhyperkalemic calves, respectively, using stepwise multivariable linear regression in the study reported here (Table 4). This finding strongly supports the validity of the experimentally determined values for $\mathrm{A}_{\text {tot }}$ and $\mathrm{p} K_{\mathrm{a}}$ in calf plasma (Constable et al., 2005), and supports the validity of the strong ion approach to explain the mechanism of an acid-base disturbance. Of interest is that the obtained coefficient estimates for phosphorus in hyperkalemic and nonhyperkalemic calves $(-0.056,-0.078)$ were higher than the coefficient estimate for total protein. This is because phosphorus has both a strong anion charge of $-1\left(\mathrm{H}_{2} \mathrm{PO}_{4}^{-}\right)$and a negative $\mathrm{pH}$-dependent nonvolatile buffer ion charge $\left(\mathrm{HPO}_{4}{ }^{2-}\right)$. As a result, it is expected that the coefficient estimate for inorganic phosphorus would lie somewhere between that of serum protein and strong anions (Table 4).

One major limitation of the strong ion approach is that it is almost impossible to measure all strong anions and cations in plasma and consequently calculate an exact value for the existing strong ion difference (Constable, 1997, 2000). In the present study, sampling conditions may have led to additional minor inaccuracies. Concentrations of sodium, potassium, ionized calcium, and chloride were determined by means of ion-selective electrodes using an automated blood gas and electrolyte analyzer (Rapidlab 865). Elevated bicarbonate concentrations were reported to interfere with chloride analyses with a reported value for the Rapidlab 865 of 0.105 per $1 \mathrm{mmol}$ increase of plasma bicarbonate (Dimeski and Clague, 2004). Using the calculated standard deviation for plasma bicarbonate concentrations of the present study population of $9.8 \mathrm{mmol} / \mathrm{L}$, it is expected that the observed chloride concentrations differed on average by $1 \mathrm{mmol} / \mathrm{L}$ from the real chloride concentration. Furthermore, the net charge on magnesium was calculated assuming that $69 \%$ of total magnesium was in the ionized form, as has been reported for adult cattle (Riond et al., 1995). This value might differ in neonatal diarrheic calves because the fraction of unbound magnesium was reported to depend on protein concentration (which differs between adult cattle and neonatal calves) as well as on changes of acid-base homeostasis (Elin et al., 1996). However, a study in horses found no difference for the fraction of ionized magnesium between foals and adults (despite lower total protein concentrations in foals) and no significant correlation between the concentration of ionized magnesium and venous blood $\mathrm{pH}$ (Berlin and Aroch, 2009). Blood samples containing potassium fluoride were used in the present study to prevent continued uptake and metabolism of glucose by erythrocytes and concomitant increases of L-lactate concentration in vitro. Studies reported that fluoride and oxalate additives lowered the plasma glucose concentration artifactually by around $10 \%$ as a result of osmotic-induced shrinkage or lysis of red blood cells (Ferrante and Kronfeld, 1994; Christopher and O'Neill, 2000). This could also have influenced the measured D- and L-lactate concentrations. However, Christopher and O'Neill (2000) found no differences for L-lactate between serum and fluoride-containing plasma samples that were processed immediately after collection and concluded that intraand extracellular L-lactate concentrations are likely the same. Whether this is true for D-lactate concentrations needs further investigation.

Although our analysis provided insight into the pathogenesis of hyperkalemia in a large population of neonatal calves with diarrhea, our study has some 
limitations. The multivariate linear regression model explained only $62 \%$ of the variation of plasma $\mathrm{K}^{+}$. This indicates that other unidentified factors may influence the occurrence of hyperkalemia. Furthermore, only laboratory parameters such as PCV, serum total protein, creatinine, and urea concentration were used to evaluate the hydration status of calves; these parameters are not as accurate in predicting hydration status in neonatal calves as the degree of enophthalmos (Constable et al., 1998; Niethammer, 2007). Inclusion of standardized assessed clinical variables (which were not available for this study population) may therefore provide a model with higher explanatory value. Pseudohyperkalemia has also been reported as an artificial elevation of plasma or serum blood potassium concentration caused by release of intracellular contents in vitro, which can occur due to poor venipuncture technique, cold storage of blood samples, after clotting due to thrombocytosis or hemolysis, and delayed separation of serum from red blood cells (Smellie, 2007). However, the effect of these potential causes of hyperkalemia was minimized in this study because plasma potassium concentrations were determined from anticoagulated blood samples immediately after collection.

\section{CONCLUSIONS}

The results of this study indicate that hyperkalemia in neonatal calves with diarrhea depends on the degree of dehydration and the nature of an existing acidosis but not on the presence of acidemia per se. D-Lactic acidosis is only rarely associated with hyperkalemia. In addition to low plasma sodium concentrations (combined with normal or elevated plasma chloride concentrations), the acidosis of hyperkalemic calves was predominantly characterized by increased blood concentrations of inorganic phosphorus, total protein, and L-lactate. Dehydration is therefore not only a major contributor to the pathogenesis of hyperkalemia but also to the acidemia that is commonly found in such calves. This finding emphasizes the central role that rehydration therapy plays in the treatment of neonatal calves with diarrhea.

\section{REFERENCES}

Adrogué, H. J., Z. Chap, T. Ishida, and J. B. Field. 1985. Role of the endocrine pancreas in the kalemic response to acute metabolic acidosis in conscious dogs. J. Clin. Invest. 75:798-808.

Adrogué, H. J., and N. E. Madias. 1981. Changes in plasma potassium concentration during acute acid-base disturbances. Am. J. Med. 71:456-467.

Amador, E., and J. Urban. 1972. Simplified serum phosphorus analyses by continuous-flow ultraviolet spectrophotometry. Clin. Chem. 18:601-604.
Amorim, J. B., M. A. Bailey, R. Musa-Aziz, G. Giebisch, and G. Malnic. 2003. Role of luminal anion and $\mathrm{pH}$ in distal tubule potassium secretion. Am. J. Physiol. Renal Physiol. 284:F381-F388.

Aronson, P. S., and G. Giebisch. 2011. Effects of $\mathrm{pH}$ on potassium: New explanations for old observations. J. Am. Soc. Nephrol. 22:1981-1989.

Berlin, D., and I. Aroch. 2009. Concentrations of ionized and total magnesium and calcium in healthy horses: Effects of age, pregnancy, lactation, $\mathrm{pH}$ and sample type. Vet. J. 181:305-311.

Brobst, D. 1986. Review of the pathophysiology of alterations in potassium homeostasis. J. Am. Vet. Med. Assoc. 188:1019-1025.

Burnell, J. M., M. F. Villamil, B. T. Uyeno, and B. H. Scribner. 1956. The effect in humans of extracellular $\mathrm{pH}$ change on the relationship between serum potassium concentration and intracellular potassium. J. Clin. Invest. 35:935-939.

Cemerikić, D., C. S. Wilcox, and G. Giebisch. 1982. Intracellular potential and $\mathrm{K}^{+}$activity in rat kidney proximal tubular cells in acidosis and $\mathrm{K}^{+}$depletion. J. Membr. Biol. 69:159-165.

Christopher, M. M., and S. O'Neill. 2000. Effect of specimen collection and storage on blood glucose and lactate concentrations in healthy, hyperthyroid and diabetic cats. Vet. Clin. Pathol. 29:22-28.

Clark, B. A., and R. S. Brown. 1995. Potassium homeostasis and hyperkalemic syndromes. Endocrinol. Metab. Clin. North Am. 24:573-591.

Constable, P. D. 1997. A simplified strong ion model for acid-base equilibria: application to horse plasma. J. Appl. Physiol. 83:297311.

Constable, P. D. 2000. Clinical assessment of acid-base status: Comparison of the Henderson-Hasselbalch and strong ion approaches. Vet. Clin. Pathol. 29:115-128.

Constable, P. D. 2002a. Calculation of variables describing plasma nonvolatile weak acids for use in the strong ion approach to acidbase balance in cattle. Am. J. Vet. Res. 63:482-490.

Constable, P. D. 2002b. The treatment of the diarrheic calf: An update. Pages 132-143 in Keynote Lectures XXII World Buiatrics Congr., Hannover, Germany. Klinik für Rinderkrankheiten, Tierärztliche Hochschule Hannover, Hannover, Germany.

Constable, P. D., H. R. Stämpfli, H. Navetat, J. Berchtold, and F. Schelcher. 2005. Use of a quantitative strong ion approach to determine the mechanism for acid-base abnormalities in sick calves with or without diarrhea. J. Vet. Intern. Med. 19:581-589.

Constable, P. D., P. G. Walker, D. E. Morin, and J. H. Foreman. 1998. Clinical and laboratory assessment of hydration status of neonatal calves with diarrhea. J. Am. Vet. Med. Assoc. 212:991-996.

Dimeski, G., and A. E. Clague. 2004. Bicarbonate interference with chloride-ion-selective electrodes. Clin. Chem. 50:1106-1107.

Elin, R. J., E. N. Hristova, S. A. Cecco, J. E. Niemela, and N. N. Rehak. 1996. Comparison of precision and effect of $\mathrm{pH}$ and calcium on the AVL and NOVA magnesium ion-selective electrodes. Scand. J. Clin. Lab. Invest. Suppl. 224:203-210.

Ewaschuk, J. B., J. M. Naylor, R. Palmer, S. J. Whiting, and G. A. Zello. 2004. D-Lactate production and excretion in diarrheic calves. J. Vet. Intern. Med. 18:744-747.

Fabiny, D. L., and G. Ertingshausen. 1971. Automated reaction-rate method for determination of serum creatinine with the Centrifichem. Clin. Chem. 17:696-700.

Ferrante, P. L., and D. S. Kronfeld. 1994. Effect of sample handling on measurement of plasma glucose and blood lactate concentrations in horses before and after exercise. Am. J. Vet. Res. 55:1497-1500.

Fisher, E. W., and A. D. McEwan. 1967. Death in neonatal calf diarrhoea. Part II: The role of oxygen and potassium. Br. Vet. J. 123:4-7.

Gasperlin, B., T. Zadnik, I. Jazbek, and J. Zust. 2002. Effects of dietary cation-anion difference on serum calcium, phosphorus and magnesium concentrations in periparturient dairy cows. Slov. Vet. Res. 39:215-225.

Gentile, A., I. Lorenz, S. Sconza, and W. Klee. 2008. Experimentally induced systemic hyperchloremic acidosis in calves. J. Vet. Intern. Med. 22:190-195. 
Good, D. W., H. Velázquez, and F. S. Wright. 1984. Luminal influences on potassium secretion: Low sodium concentration. Am. J. Physiol. 246:F609-F619.

Good, D. W., and F. S. Wright. 1979. Luminal influences on potassium secretion: Sodium concentration and fluid flow rate. Am. J. Physiol. 236:F192-F205.

Graber, M. 1993. A model of the hyperkalemia produced by metabolic acidosis. Am. J. Kidney Dis. 22:436-444.

Grude, T. 2003. Concentrations of L- and D-lactate in serum, urine, and rumen liquid in calves, with special reference to "ruminal drinkers". Tierarztl. Prax. Ausg. G Grosstiere Nutztiere 31:72-77.

Grünberg, W., P. Constable, U. Schröder, R. Staufenbiel, D. Morin, and M. Rohn. 2005. Phosphorus homeostasis in dairy cows with abomasal displacement or abomasal volvulus. J. Vet. Intern. Med. 19:894-898.

Grünberg, W., S. S. Donkin, and P. D. Constable. 2011. Periparturient effects of feeding a low dietary cation-anion difference diet on acidbase, calcium, and phosphorus homeostasis and on intravenous glucose tolerance test in high-producing dairy cows. J. Dairy Sci. 94:727-745.

Joyce, P. W., W. K. Sanchez, and J. P. Goff. 1997. Effect of anionic salts in prepartum diets based on alfalfa. J. Dairy Sci. 80:28662875 .

Kaneko, J. J., J. W. Harvey, and M. L. Bruss. 2008. Blood analyte reference values in large animals. Pages $882-888$ in Clinical Biochemistry of Domestic Animals. 6th ed. Academic Press/Elsevier, San Diego, CA

Kasari, T. R., and J. M. Naylor. 1984. Metabolic acidosis without clinical signs of dehydration in young calves. Can. Vet. J. 25:394-399.

Kasari, T. R., and J. M. Naylor. 1986. Further studies on the clinical features and clinicopathological findings of a syndrome of metabolic acidosis with minimal dehydration in neonatal calves. Can. J. Vet. Res. 50:502-508.

Kunst, A., B. Draeger, and J. Ziegenhorn. 1984. UV methods with hexokinase and glucose-6-phosphate dehydrogenase. Pages 163172 in Methods of Enzymatic Analysis. Vol. VI, Metabolites 1: Carbohydrates. 3rd ed. H. U. Bergmeyer, ed. Verlag Chemie, Weinheim, Germany.

Lemann, J., J. R. Litzow, and E. J. Lennon. 1966. The effects of chronic acid loads in normal man: Further evidence for the participation of bone mineral in the defense against chronic metabolic acidosis. J. Clin. Invest. 45:1608-1614.

Lewis, L. D., and R. W. Phillips. 1972. Water and electrolyte losses in neonatal calves with acute diarrhea. A complete balance study. Cornell Vet. 62:596-607.

Lewis, L. D., and R. W. Phillips. 1973. Diarrheic induced changes in intracellular and extracellular ion concentrations in neonatal calves. Ann. Rech. Vet. 4:99-111.

Lorenz, I. 2004. Influence of D-lactate on metabolic acidosis and on prognosis in neonatal calves with diarrhoea. J. Vet. Med. A Physiol. Pathol. Clin. Med. 51:425-428.

Lorenz, I., A. Gentile, and W. Klee. 2005. Investigations of D-lactate metabolism and the clinical signs of D-lactataemia in calves. Vet. Rec. 156:412-415.

Lorenz, I., I. Hartmann, and A. Gentile. 2003. Determination of Dlactate in calf serum samples-An automated enzymatic assay. Comp. Clin. Pathol. 12:169-171.

Major, R. H. 1923. Potassium fluoride as a preservative for blood. J. Am. Med. Assoc. 81:1952.

Mann, C. K., and J. H. Yoe. 1956. Spectrophotometric determination of magnesium with sodium 1-azo-2-hydroxy-3-(2,4dimethylcarboxanilido)-naphthalene-1'-(2-hydroxybenzene-5sulfonate). Anal. Chem. 28:202-205.
Müller, K. R., A. Gentile, W. Klee, and P. D. Constable. 2012. Importance of the effective strong ion difference of an intravenous solution in the treatment of diarrheic calves with naturally acquired acidemia and strong ion (metabolic) acidosis. J. Vet. Intern. Med. 26:674-683.

Niethammer, F. M. 2007. Untersuchungen zur Dehydratation bei Kälbern mit akuter Diarrhoe unter Berücksichtigung ausgewählter klinischer und labordiagnostischer Parameter. Doctoral Thesis. Ludwig-Maximilians University, Munich, Germany.

Niwa, T. 1996. Organic acids and the uremic syndrome: Protein metabolite hypothesis in the progression of chronic renal failure. Semin. Nephrol. 16:167-182.

Noll, F. 1966. Methode zur quantitativen Bestimmung von L (+)-Lactat mittels Lactat-Dehydrogenase und Glutamat-Pyruvat-Transaminase. Biochem. Z. 346:41-49.

O'Connor, L. R., K. L. Klein, and J. E. Bethune. 1977. Hyperphosphatemia in lactic acidosis. N. Engl. J. Med. 297:707-709.

Opie, L. H., M. Thomas, P. Owen, and G. Shulman. 1972. Increased coronary venous inorganic phosphate concentrations during experimental myocardial ischemia. Am. J. Cardiol. 30:503-513.

Oster, J. R., G. O. Perez, A. Castro, and C. A. Vaamonde. 1980 Plasma potassium response to acute metabolic acidosis induced by mineral and nonmineral acids. Miner. Electrolyte Metab. 4:28-36.

Oster, J. R., G. O. Perez, and C. A. Vaamonde. 1978. Relationship between blood $\mathrm{pH}$ and potassium and phosphorus during acute metabolic acidosis. Am. J. Physiol. 235:F345-F351.

Riond, J. L., N. Kocabagli, U. E. Spichiger, and M. Wanner. 1995 The concentration of ionized magnesium in serum during the periparturient period of non-paretic dairy cows. Vet. Res. Commun. 19:195-203.

Rogers, T. A., and A. E. Wachenfeld. 1958. Effect of physiologic acids on electrolytes in rat diaphragm. Am. J. Physiol. 193:623-626.

Schelcher, F., S. Marcillaud, J.-P. Braun, M. Contrepois, J.-F. Valarcher, and H. Navetat. 1998. Metabolic acidosis without dehydration and no or minimal diarrhoea in suckler calves is caused by hyper-D-lactatemia. Pages 371-374 in Proc. XX World Buiatrics Congr., Sydney, Australia. New Generation Print \& Copy, Brunswick East, Victoria, Australia.

Siggaard-Andersen, O. 1977. The van Slyke equation. Scand. J. Clin. Lab. Invest. Suppl. 146:15-20.

Smellie, W. S. 2007. Spurious hyperkalaemia. BMJ 334:693-695.

Sterns, R. H., M. Cox, P. U. Feig, and I. Singer. 1981. Internal potassium balance and the control of the plasma potassium concentration. Medicine 60:339-354.

Sweeney, R. W. 1999. Treatment of potassium balance disorders. Vet Clin. North Am. Food Anim. Pract. 15:609-617.

Talke, H., and G. E. Schubert. 1965. Enzymatische Harnstoffbestimmung in Blut und Serum im optischen Test nach Warburg. Klin. Wochenschr. 43:174-175.

Thomas, L. J. Jr. 1972. Algorithms for selected blood acid-base and blood gas calculations. J. Appl. Physiol. 33:154-158.

Trefz, F. M., A. Lorch, M. Feist, C. Sauter-Louis, and I. Lorenz. 2013. The prevalence and clinical relevance of hyperkalaemia in calves with neonatal diarrhoea. Vet. J. 195:350-356.

Velázquez, H., F. S. Wright, and D. W. Good. 1982. Luminal influences on potassium secretion: Chloride replacement with sulfate. Am. J. Physiol. 242:F46-F55.

Weichselbaum, T. E. 1946. An accurate and rapid method for the determination of proteins in small amounts of blood serum and plasma. Am. J. Clin. Pathol. 10:40-49.

Weldon, A. D., N. S. Moise, and W. C. Rebhun. 1992. Hyperkalemic atrial standstill in neonatal calf diarrhea. J. Vet. Intern. Med. 6:294-297. 